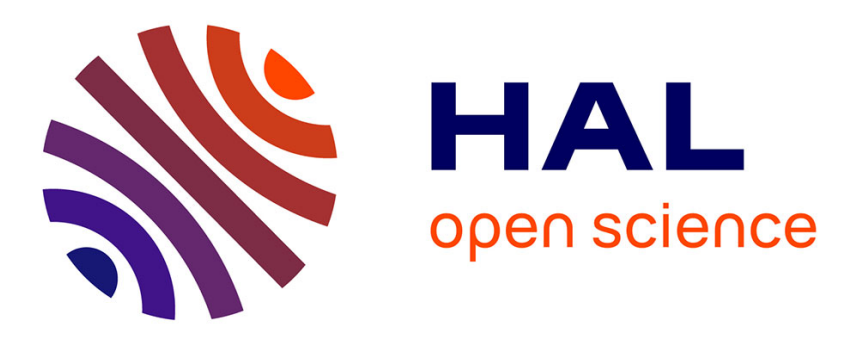

\title{
Study of the interaction polybutadiene/fillers using inverse gas chromatography
}

Rachel Calvet, Sylvie del Confetto, Henri Balard, Eric Brendle, Jean-Baptiste

Donnet

\section{- To cite this version:}

Rachel Calvet, Sylvie del Confetto, Henri Balard, Eric Brendle, Jean-Baptiste Donnet. Study of the interaction polybutadiene/fillers using inverse gas chromatography. Journal of Chromatography A, 2012, 1253, pp.164-170. 10.1016/j.chroma.2012.07.002 . hal-01688412

\section{HAL Id: hal-01688412 https://hal.science/hal-01688412}

Submitted on 20 Nov 2018

HAL is a multi-disciplinary open access archive for the deposit and dissemination of scientific research documents, whether they are published or not. The documents may come from teaching and research institutions in France or abroad, or from public or private research centers.
L'archive ouverte pluridisciplinaire HAL, est destinée au dépôt et à la diffusion de documents scientifiques de niveau recherche, publiés ou non, émanant des établissements d'enseignement et de recherche français ou étrangers, des laboratoires publics ou privés. 


\title{
Study of the interaction polybutadiene/fillers using inverse gas chromatography
}

\author{
Rachel Calvet $^{\mathrm{a}, *}$, Sylvie Del Confetto ${ }^{\mathrm{a}}$, Henri Balard ${ }^{\mathrm{b}, \mathrm{c}}$, Eric Brendléc ${ }^{\mathrm{c}}$, Jean-Baptiste Donnet ${ }^{\mathrm{b}}$ \\ a Université de Toulouse, Mines Albi, CNRS, Centre RAPSODEE, Campus Jarlard, F-81013 Albi Cedex 09, France \\ ${ }^{\mathrm{b}}$ ENSCMu/ENSISA, 11 rue A. Werner, 68200 Mulhouse, France \\ ${ }^{c}$ ADSCIENTIS SARL, 10 rue A. Kastler, 68280 Wittelsheim, France
}

\section{A B S T R A C T}

In this study, the coupling of IGC-ID analysis and carbon blacks impregnation with increasing ratios of polymer allow us to highlight the affinity of the polymer to the solid surface. The variations of the dispersive component of the surface energy and of the nanomorphology index are monitored versus the degree of carbon black impregnation. A clear correlation between the decrease in the dispersive component of the surface energy and the increase in the nanomorphological index is observed. The PBu macromolecules shield progressively the slot shaped sites on the carbon blacks surface. IGC reveals clear differences in surface properties between CB of different grades.

\section{Introduction}

The reinforcing properties of carbon blacks are closely related to the interaction polymer/carbon black surface but also to the fractal nature of the particulate filler aggregates $[1,2]$ and filler networking $[3,4]$. So, a special attention was also given to gain insight into the relationship between disordered filler structures with different length scales and specific microscopic effects contributing to carbon black reinforcement $[5,6]$. An improved understanding of the particulate mechanisms of reinforcement is relevant in material science [7].

Beside these well-investigated morphological effects, the surface activity of carbon blacks plays a key role in reinforcement of elastomers by controlling the polymer-filler phase bonding and the filler-filler interaction [2]. Despite this importance of the surface activity, reinforcing fillers are characterised mainly by their specific surface area related to the mean particle size and by their DBP number (adsorption of dibutyl phthalate) which is bound to the aggregate structure. Hence the surface activity of CBs cannot yet be assessed by any standard molecular parameter [2].

Many efforts were made to judge the level of the surface activity of carbon blacks. The first one was made, in particular, on measurements done by IGC in infinite dilution conditions [8-12]. Lansiger and Donnet $[8,12]$ have revealed a relationship between the dispersive component of surface energy assessed by IGC-ID and the reinforcing properties of some carbon blacks, the higher the

\footnotetext{
* Corresponding author. Tel.: +33 563493064; fax: +33 563493025

E-mail address: calvet@mines-albi.fr (R. Calvet).
}

dispersive component, the higher the reinforcing effect. But IGC-ID analysis mainly reflects the sites having the highest energies [13], and so, delivers no quantitative information concerning the number of these latter adsorption sites.

To gain a further understanding, many investigators have employed adsorption isotherm measurement using nitrogen [14] and ethene [15] or IGC at finite concentration conditions $[10,16,17]$. They have then assessed the carbon black surface heterogeneity in terms of distribution functions of the adsorption energies. However, due to the variability of the type and origin of the carbon black samples, the nature of the adsorbate, but also of the computing method, it is difficult to extract a clear conclusion from this last data. Nevertheless, a trend is observed, the higher the specific surface area, the higher the number of sites with a high level of energy, as noted by Schröder et al. who observed that the N115 sample presents more energetic sites than samples exhibiting a lower specific surface area like the N550. Hence, adsorption analytical methods suggest that carbon blacks presenting a high energetic surface are the most efficient as regards the reinforcing power.

Surface heterogeneity can be evaluated not only in terms of surface activity, but is also dependent on their surface geometry as shown by Vilgis and Heinrich [18] and this plays an important role in the interaction of a macromolecule with a solid surface.

Upon adsorption on a surface, a polymer chain loses conformational entropy and this loss will be more important on a smooth surface than on a rough one because on the former, the polymer chain has to stretch out and accordingly its entropy loss is high, whereas on the latter the polymer chain can curve into the rough surface leading to lower entropy loss. Numerous investigations of the surface roughness of carbon black have been carried out with 


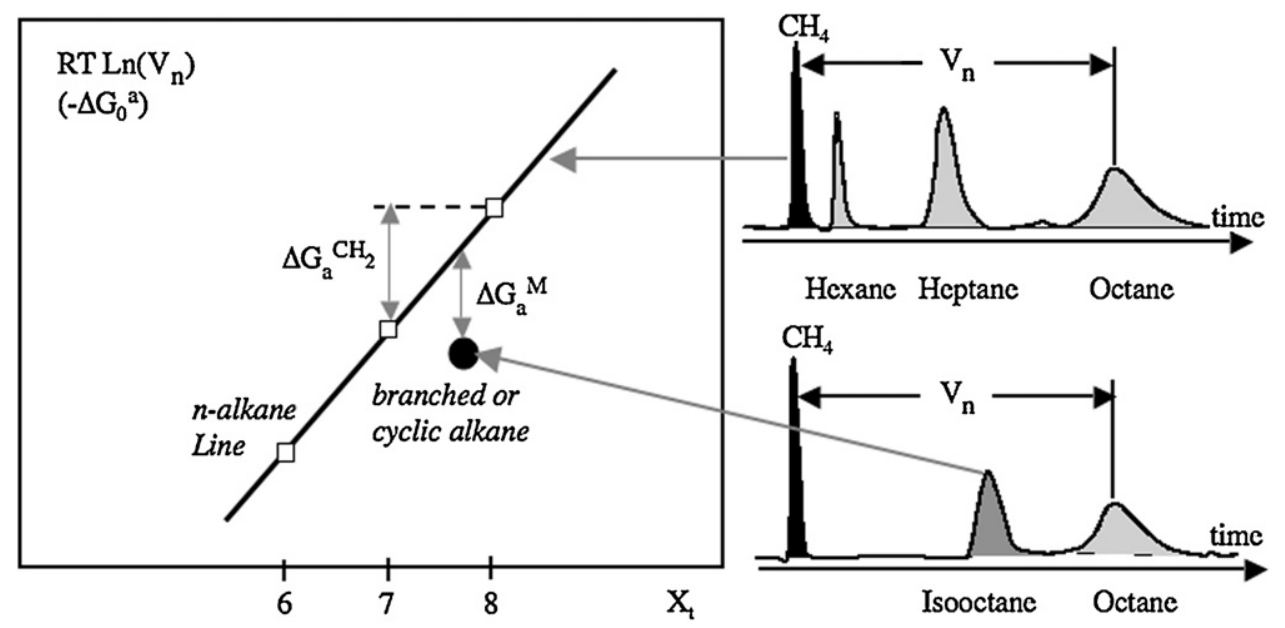

Fig. 1. Variation of the free energies of adsorption of the probes with their topological indexes, $X_{\mathrm{t}}$ [39]: relation with some experimental chromatograms and principle of the determination of main IGC-ID parameters, $\Delta G_{a}^{\mathrm{CH}_{2}}$ and $\Delta G_{a}^{M}$.

different techniques like gas adsorption [19-25], small angle X-ray and neutron scattering (SAXS and SANS) [26-28] or atomic force or scanning tunnel microscopy (AFM and STM) $[29,30]$. Based on these last techniques, Donnet and Custodero have proposed that the carbon black surface is covered by "fish scale" like structures corresponding to surface graphitic domains. The results are contradictory and range from nearly smooth carbon black particle surfaces to very rough surfaces, even with the same techniques.

It is worth pointing out that all the adsorption measurements were performed using small molecular probes [8-12], which are far from an actual macromolecular chain as regards both the functionality and the conformation.

Recently, it was demonstrated for talc and silica that coupling of IGC-ID analysis and progressive polymer impregnation permits a titration of the sites to which the polymer chains have access and so quantifies the affinity of a polymer to the solid surface [31,35-37]. Using this new approach, the surface is probed with a macromolecule and small molecules (IGC probes: alkanes and branched or cyclic alkanes), which delivers information on the interaction level between the polymer and the surface through the dispersive component of the surface energy and the surface morphology (index of nanomorphology).

In the present work, the same approach was applied to examine the interaction between a polybutadiene ( $\mathrm{PBu}$ ) and a set of carbon black samples. The variations of the dispersive component of the surface energy and of the nanomorphology index were monitored versus the degree of impregnation.

\section{IGC-ID theory}

Inverse gas chromatography (IGC) is a useful method for studying the surface properties of finely divided solids [13,41]. It is based on the injection of molecules of a known nature, called probes, into a column packed with a solid to be tested. The present study has been carried out at infinite dilution (IGC-ID).

The net retention volume of the probe $\left(V_{\mathrm{n}}\right)$ is recorded which reflects the level of interaction between the solid surface and the isolated probe [38]. The free energy of adsorption of the probe is directly related to the retention volume and to the net retention time by the following equation.

$\Delta G_{0}^{a}=-R T \operatorname{Ln}\left(V_{\mathrm{n}}\right)+C=-R T \operatorname{Ln}\left(J \times D_{\mathrm{m}} \times \frac{T_{\mathrm{c}}}{T_{\mathrm{a}}} \times \frac{\eta\left(T_{\mathrm{c}}\right)}{\eta\left(T_{\mathrm{a}}\right)} \times t_{\mathrm{r}}\right)+C$ where $J$ is the James Martin coefficient, which takes into account the compressibility of the carrier gas, $D_{\mathrm{m}}$ the measured flow rate with an electronic flow metre, $T_{\mathrm{c}}$ and $T_{\mathrm{a}}$ the column and the room temperatures, $\eta(T)$ the gas carrier viscosity, $t_{\mathrm{r}}$ the net retention time of the probe and $C$ a constant depending on a reference state.

Fig. 1 describes the principle of the determination of main parameters, $\Delta G_{a}^{\mathrm{CH}_{2}}$ and $\Delta G_{a}^{M}$ that can be acquired through IGC-ID technique and relates respectively to the non-specific interaction and the surface morphology of the solid surface.

The $n$-alkane line is obtained by plotting the free adsorption energy versus the number of carbon atoms of the injected alkane probes, its slope corresponds to the increment of free energy per methylene groups $\left(\Delta G_{a}^{\mathrm{CH}_{2}}\right)$ as depicted in Fig. 1. From this parameter, the dispersive component of the surface energy was determined using the Dorris and Gray approach [40]. The dispersive component of the surface energy $\left(\gamma_{s}^{d}\right)$ can be readily calculated according to the following equation.

$\gamma_{s}^{d}=\frac{\left(\Delta G_{a}^{\mathrm{CH}_{2}}\right)^{2}}{4 N^{2} a_{\mathrm{CH}_{2}}^{2} \gamma_{\mathrm{CH}_{2}}}$

where $N$ is Avogadro's number, $a_{\mathrm{CH}_{2}}$ is the area covered by one methylene group $\left(0.06 \mathrm{~nm}^{2}\right)$, and $\gamma_{\mathrm{CH}_{2}}$ is the surface energy of pure methylene group surface, i.e., polyethylene, $\gamma_{\mathrm{CH}_{2}}=35.6+$ $0.058(293-T)$, in $\mathrm{mJ} / \mathrm{m}^{2}$ ( $T$ the temperature in $\left.\mathrm{K}\right)$.

The parameter $\gamma_{s}^{d}$ is directly related to the surface polarisability of the solid surface [13]. Of course, probes other than the linear apolar n-alkanes may be used to assess the interaction potential of a solid surface. Among these probes, branched or cyclic isomers of the n-alkanes that can only exchange non-specific interaction like linear ones, are of a main interest for testing the surface morphology at a molecular scale. In particular, Brendle and Papirer [39] have shown that such isomers exhibit much lower retention times than the corresponding linear alkanes for solids having a lamellar structure such as crystalline silicas [41] or talc [42]. This difference of behaviour between linear and branched cyclic alkane probes was attributed to the fact that linear probes have access to the slot like adsorption sites present on the lateral surfaces of these lamellar solids whereas branched or cyclic alkanes are excluded for steric effect and so exhibit a much lower energy of interaction. These slot like sites are the result of a lack of one crystalline plane leading to a slot having a dimension of about twice the interplanar distance that means a nanometric or subnanometric dimension.

Of course, the size exclusion effect is closely related to both the molecular shape of the probe and the surface morphology. In order 
Table 1

Main characteristics of the studied carbon blacks.

\begin{tabular}{|c|c|c|c|c|c|}
\hline Carbon blacks & $\begin{array}{l}\text { BET } N_{2} \text { area } \\
\left(\mathrm{m}^{2} / \mathrm{g}\right)\end{array}$ & $\begin{array}{l}\text { Mean particle } \\
\text { size }(\mathrm{nm})\end{array}$ & $\begin{array}{l}\text { CTAB area } \\
\left(\mathrm{m}^{2} / \mathrm{g}\right)\end{array}$ & $\begin{array}{l}\text { Iodide adsorption } \\
(\mathrm{mg} / \mathrm{g})\end{array}$ & $\begin{array}{l}\text { DBP adsorption } \\
(\mathrm{ml} / 100 \mathrm{~g})\end{array}$ \\
\hline N539 & 41 & $\sim 50$ & 41 & 42 & 112 \\
\hline N330 & 82 & $\sim 30$ & 83 & 84 & 100 \\
\hline N326 & 85 & $\sim 27$ & 81 & 84 & 69 \\
\hline N347 & 90 & $\sim 30$ & 88 & 91 & 125 \\
\hline N115 & 140 & $\sim 18$ & 128 & 145 & 113 \\
\hline
\end{tabular}

to take into account the shape and structure influence, brendle and Papirer [39] have put forward some topology indexes $X_{t}$. The size exclusion effect leads to a decrease in the free energy of adsorption when comparing it with that of a virtual linear alkane having the same topological index $\left(X_{\mathrm{t}}\right)$ as depicted in Fig. 1 and leads to a decrement of free energy $-\Delta G_{a}^{M}$. Balard et al. [13] suggested an index of surface nanomorphology, according to the following equation:

$I_{\mathrm{M}}\left(X_{\mathrm{t}}\right)=\exp \left(\frac{-\Delta G_{a}^{M}}{R T}\right)$

when $I_{\mathrm{M}}\left(X_{\mathrm{t}}\right)$ is equal to 1 , that means $-\Delta G_{a}^{M}$ is equal or near zero, the linear and branched or cyclic probes have access to the same surface, the solid surface can be considered flat at the molecular level, for example for some fumed silicas [41]. An $I_{M}\left(X_{t}\right)$ lower than 1 is the result of a size exclusion phenomena between linear and branched or cyclic probes due to a rough surface, it occurs with solids like talc. When the $I_{\mathrm{M}}$ overcomes 1 , a thick layer of polymer is deposited on the solid surface and an absorption of the probe into this layer occurs [31].

\section{Experimental part}

\subsection{Carbon blacks}

For the present work, five carbon blacks from the Continental Carbon Company (Texas, USA), were selected. Their main characteristics are reported in Table 1 . The specific surface area was measured with nitrogen gas using an ASAP 2000 instrument from Micromeritics according to the ASTM standard procedure (ASTM D 3037) [32]. The CTAB (cetyltrimethylammonium bromide) surface area, the iodide and the DBP (dibutyl phthalate) adsorption values were determined according to the ASTM standard procedures (ASTM D 3765 and ASTM D 1510) [33,34].

\subsection{Impregnation protocol}

The impregnation of carbon black were mainly done using a polybutadiene from Sigma Aldrich $(M w=40,000 \mathrm{~g} / \mathrm{mol})$.

A polybutadiene solution having a known concentration in dichloromethane was prepared. A given amount of carbon black was dispersed in $25 \mathrm{ml}$ of the same solvent. By adding increasing volumes of the $\mathrm{PBu}$ solution to these carbon black dispersions, a large scale of impregnation ratios ( $\tau$ expressed in $\mathrm{mg} / \mathrm{g}$ ) could be examined. After the complete evaporation of the solvent, IGC columns were filled with the PBu impregnated carbon black and conditioned at $120^{\circ} \mathrm{C}$. This impregnation protocol is well described in previous studies [31,35-37].

From the $\tau$ values, the coverage ratios $\left(n_{\mathrm{MU}}\right)$ of the surface in terms of monomer units per square nanometer $\left(\mathrm{MU} / \mathrm{nm}^{2}\right)$ were computed according to the following equation:

$n_{\mathrm{MU}}=\tau \frac{N}{1000 \times M_{\mathrm{MU}} S \times 10^{18}}=\tau \frac{602.3}{M_{\mathrm{MU}} S}$ where $N$ is the Avogadro number, $M_{\mathrm{MU}}$ the Bu monomer unit molecular weight $(54 \mathrm{~g} / \mathrm{mol})$ and $S$ the specific surface area of the studied solid measured with nitrogen, $\tau$ is given in $\mathrm{mg} / \mathrm{g}$ or \%.

The monomer unit molecular area $\left(a_{\mathrm{MU}}\right.$ in $\left.\mathrm{nm}^{2}\right)$ was assessed according to Eq. (5) from the molecular volume of the monomer unit, computed from the polymer bulk density $\left(d\right.$ in $\left.\mathrm{g} / \mathrm{cm}^{3}\right)$ and the monomer unit molecular weight $\left(M_{\mathrm{MU}}\right.$ in $\left.\mathrm{g} / \mathrm{mol}\right)$, considering that one monomer unit is a cube:

$a_{\mathrm{MU}}=k\left(\frac{M_{\mathrm{MU}}}{d \times 602.3}\right)^{2 / 3}$

where $d$ is equal to $0.95 \mathrm{~g} / \mathrm{cm}^{3}$ for PBu.

Using this method, the molecular area $\left(a_{\mathrm{MU}}\right)$ is generally underestimated of about $20 \%$, so the value of $k$ was fixed to 1.2 .

Knowing the MU surface area $\left(a_{\mathrm{MU}}\right)$ in $\mathrm{nm}^{2}$, the theoretical number of monomer unit per square nanometer of carbon black necessary to form a "so called" monomer unit monolayer could be computed, according to the following equation:

$N_{\mathrm{MU}}=\frac{1}{a_{\mathrm{MU}}}$

According to Eqs. (5) and (6), the values of both MU molecular area $\left(a_{\mathrm{MU}}\right)$ and the MU number per $\mathrm{nm}^{2}$ for the monolayer formation $\left(N_{\mathrm{MU}}\right)$ are equal respectively to $0.25 \mathrm{~nm}^{2}$ and 4.0 for $\mathrm{PBu}$. This approach delivers a rough approximation of the area occupied by a MU on the solid surface, because the MUs are linked in the macromolecule, they are not independent entities like the nitrogen molecule in the case of BET specific area measurement.

\subsection{Experimental IGC conditions}

The agglomerated impregnated carbon black powder was gently crushed and sieved. Particles having diameter comprised between 200 and $400 \mu \mathrm{m}$ were retained. The powder was poured into stainless steel columns, $10 \mathrm{~cm}$ long and $2 \mathrm{~mm}$ internal diameter, which were gently taped in order to obtain a regular filling. Hence, chromatographic beds were prepared, having a convenient permeability corresponding to a pressure drop lower than $50 \mathrm{kPa}$ with a flow rate of the carrier gas of about $30 \mathrm{ml} / \mathrm{min}$.

Two Agilent 6890 gas chromatographs, each fitted with two flame ionisation detectors (FIDs), were used with helium carrier gas. The injector and detector were heated to $180^{\circ} \mathrm{C}$. All the columns were conditioned overnight at $120^{\circ} \mathrm{C}$ and the analyses made at $150^{\circ} \mathrm{C}$. Net retention times were calculated by subtracting the retention time of a non-retained molecule, methane, from the retention times of the probes. Selected IGC probes - n-alkanes and cycloalkane - are purum products from Aldrich-Sigma. 


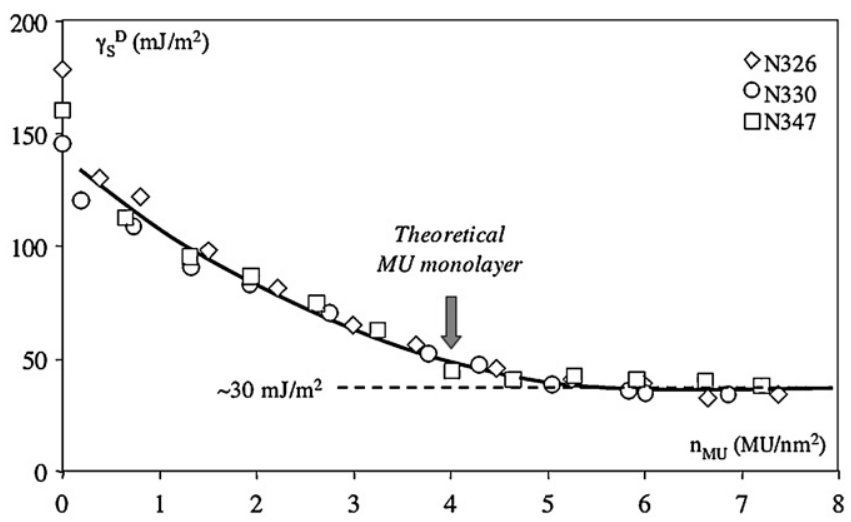

Fig. 2. Variation of the dispersive component $\left(\gamma_{s}^{d}\right)$ of PBu impregnated carbon blacks of N326, N330 and N347 grades, with the MU coverage ratio $\left(n_{\mathrm{UM}}\right)$. The black arrow indicates the theoretical value for the MU monolayer.

\section{Results}

\subsection{Coupling of PBu controlled impregnation and IGC-ID analysis} for N326, N330 and N347 carbon black grades

\subsubsection{Variation of the dispersive component of the surface energy with the impregnation ratio}

Firstly, three carbon black grades, N326, N330 and N347, were examined. These samples have the same mean particle size or specific surface area but differ in their structure as measured by DBP adsorption.

The variation of the dispersive component of the surface energy $\left(\gamma_{s}^{d}\right)$ of these PBu impregnated carbon blacks with the MU coverage ratio expressed in number of MU per surface unit $\left(n_{\mathrm{UM}}\right)$, is depicted in Fig. 2.

Three main conclusions have to be given on the variation of the dispersive component with the MU coverage ratio:

1) The $\gamma_{s}^{d}$ values corresponding to the initial unmodified samples differ only slightly between the 3 different carbon blacks, around $160 \mathrm{~mJ} / \mathrm{m}^{2}$.

2) For the impregnated samples, the variation of $\gamma_{s}^{d}$ follows the same trend for the 3 studied samples and decreases monotonously until the MU deposited covers the whole of the carbon black surface, when $n_{\mathrm{UM}}$ (equal to $5 \mathrm{MU} / \mathrm{nm}^{2}$ ) exceeds $20 \%$ of the theoretical value $\left(4 \mathrm{MU} / \mathrm{nm}^{2}\right)$. Hence it has been showed that the PBu adsorbs at first on the more energetic sites.

3) Beyond this threshold, $\gamma_{s}^{d}$ becomes constant and equal to about $30 \mathrm{~mJ} / \mathrm{m}^{2}$, a value characteristic of an apolar polymer surface formed by the PBu layer.

In other words, the deposited PBu shields progressively the sites of adsorption, in which alkane probes could be inserted. This effect could be also quantified using the index of nanomorphology.

\subsubsection{Variation of the index of nanomorphology with the impregnation ratio}

The variation of the index of nanomorphology $\left(I_{\mathrm{M}}\right)$ measured with cyclooctane probe, of PBu impregnated carbon blacks of N326, N330 and N347 grades, with the MU coverage ratio expressed in number of MU per surface unit $\left(n_{\mathrm{UM}}\right)$, is depicted in Fig. 3.

Here, four main conclusions have to be done on the variation of the index of nanomorphology with the MU coverage ratio:

1) The $I_{M}$ values, corresponding to the initial unmodified samples are equal to 0.4 , proving the presence of numerous insertion sites at the edge of the graphitic structures.

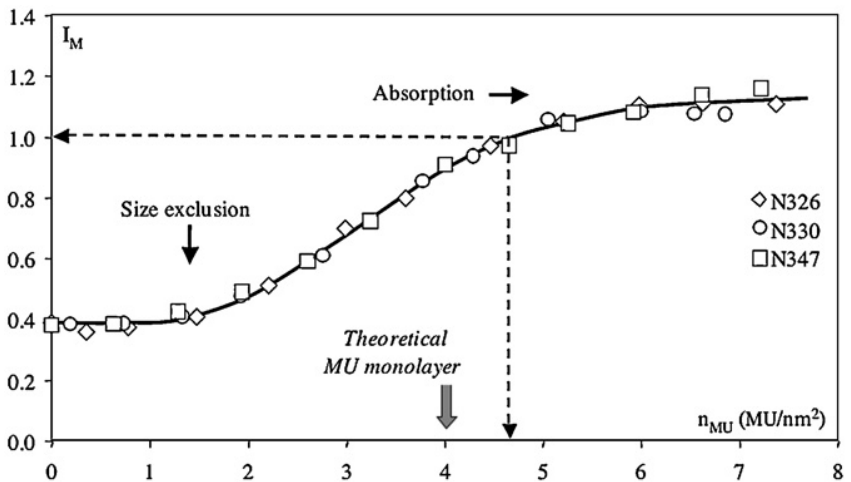

Fig. 3. Variation of the index of surface morphology $\left(I_{\mathrm{M}}\right)$ of PBu impregnated carbon blacks of N326, N330 and N347 grades, with the MU coverage ratio $\left(n_{\mathrm{UM}}\right)$.

2) For the impregnated samples, a "S" shaped variation is observed for the 3 samples studied with the MU coverage ratio, proving again that these samples exhibit nearly identical surface structures.

3) Two thresholds are registered, around $1.5 \mathrm{MU} / \mathrm{nm}^{2}$ and $5.5 \mathrm{MU} / \mathrm{nm}^{2}$. Obviously the second threshold is related to the formation of the continuous PBu layer. The first threshold shows that about $27 \%$ of the total surface corresponds to similar strong interacting sites presenting the same geometry, responsible of the size exclusion effect. Below $1.5 \mathrm{MU} / \mathrm{nm}^{2}$, the $I_{\mathrm{M}}$ remains very low indicating that the linear alkanes have access to sites where the cyclooctane is excluded due to steric encumbrance.

4) The index of morphology $I_{M}$ overcomes a value of $1 \mathrm{MU} / \mathrm{nm}^{2}$ slightly before the number necessary to form a continuous PBu layer and reaches a value close to 1.2 for $7 \mathrm{MU} / \mathrm{nm}^{2}$, showing preferential absorption of the cyclic probe, in comparison with linear ones. This preferential absorption starts to take place in the PBu film present at the surface.

Though the study of the variation of the index of morphology with the MU coverage ratio corroborates and completes the assumption deduced from the variation of the $\gamma_{s}^{d}$ values, it also shows that the PBu at first starts to adsorb and shield the sites having the highest energy, and in which linear alkane can be inserted, and thereafter covers progressively the less energetic sites until all of the carbon black surface will be covered by the MU.

We will now examine how the grade of the carbon black studied will influence the variations of these two parameters, $\gamma_{s}^{d}$ and $I_{\mathrm{M}}$, with the increase of the MU coverage ratio.

\subsection{IGC-ID analysis of PBu impregnated N115, N330 and N539 carbon blacks}

\subsubsection{Variation of the dispersive component of the surface energy with the impregnation ratio}

In the second part of the study, the carbon blacks examined, N115, N330 and N539, differ in mean particles size and specific surface area ranging for example with nitrogen from to 41 to $140 \mathrm{~m}^{2} / \mathrm{g}$.

The variation of the dispersive component of the surface energy $\left(\gamma_{s}^{d}\right)$ of these PBu impregnated carbon blacks, with the MU coverage ratio, expressed in number of MU per surface unit $\left(n_{\mathrm{UM}}\right)$, is depicted in Fig. 4.

It immediately appears that N539 sample behaves like the N330 one as regards to the variation of $\gamma_{s}^{d}$ with the MU coverage ratio. On the contrary, the initial N115 carbon black exhibits a much higher $\gamma_{s}^{d}$ value than the others studied samples. Moreover the $\gamma_{s}^{d}$ of the impregnated sample then decreases rapidly. Thereafter, it behaves like the other grades. Beyond $5 \mathrm{MU} / \mathrm{nm}^{2}$, the dispersive surface energy becomes equal to the PBu one. We will now consider the 


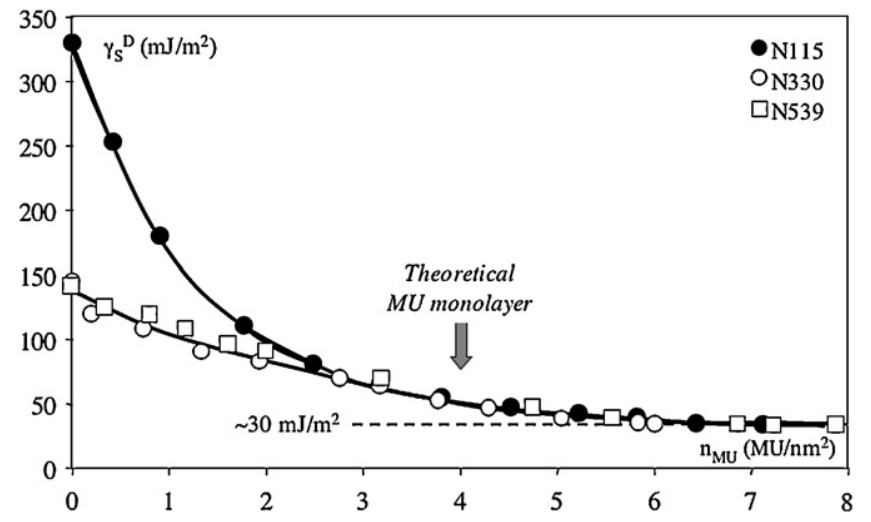

Fig. 4. Variation of the dispersive component of the surface energy $\left(\gamma_{s}^{d}\right)$ of PBu impregnated carbon blacks of N115, N330 and N539 grades, with the MU coverage ratio $\left(n_{\mathrm{UM}}\right)$.

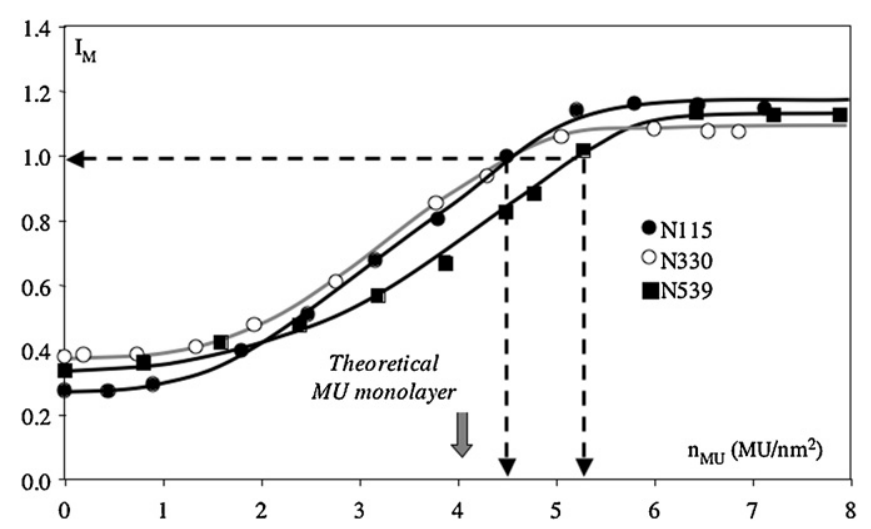

Fig. 5. Variation of the index of surface morphology $\left(I_{\mathrm{M}}\right)$ of PBu impregnated carbon blacks of N115, N330 and N539 grades, with the MU coverage ratio ( $\left.n_{\mathrm{UM}}\right)$.

variation of the index of nanomorphology with the MU coverage ratio.

4.2.2. Variation of the index of nanomorphology with the impregnation ratio of N115, N330 and N539 samples

The variation of the index of nanomorphology $\left(I_{\mathrm{M}}\right)$ measured with a cyclooctane probe of $\mathrm{PBu}$ impregnated carbon blacks of N115, N330 and N539 grades, with the MU coverage ratio, expressed in number of MU per surface unit $\left(n_{\mathrm{UM}}\right)$, is depicted in Fig. 5.

Considering the initial samples, it is observed that N539 and N330 samples show very close $I_{M}$ values, whereas N115 sample exhibits a lower value. PBu impregnation induces a similar "S" shaped variation for the three samples, but they do not follow the same trend.

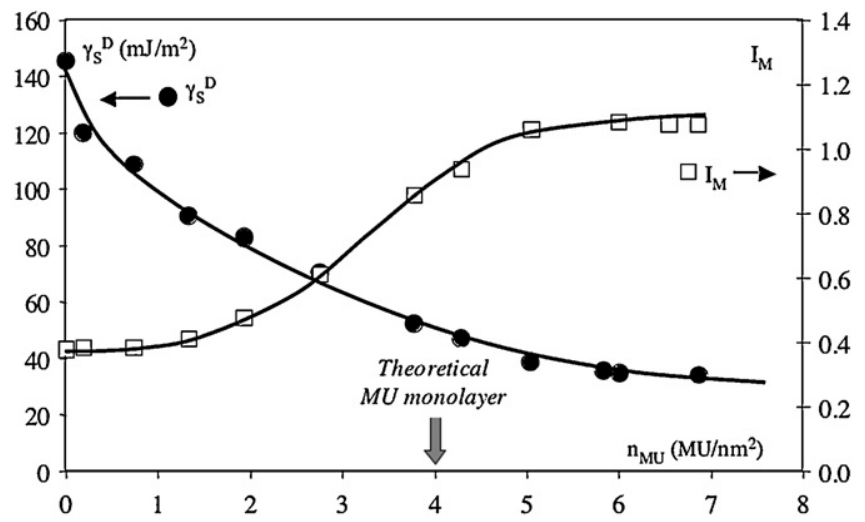

Fig. 7. Variations of both $\gamma_{s}^{d}$ and $I_{\mathrm{M}}$ parameters with the impregnation ratio, observed for the N115 sample.

We have observed that the N330 and N539 samples behaves almost identically so long the MU coverage is lower $2 \mathrm{MU} / \mathrm{nm}^{2}$, thereafter they differ completely, the N539 showing a slower variation whereas the N330 now follows the same trend as the N115 sample. For the latter, the $I_{M}$ value remains quite constant up to a coverage ratio of $1 \mathrm{MU} / \mathrm{nm}^{2}$ and then increases quickly joining the curve of the N330 sample.

Hence both trends of the dispersive component of the surface energy and of the index of nanomorphology testify that the surface structure of these three samples differs by their capacity of interaction and their surface geometry. An interpretation has to be found considering the surface model structures proposed for the carbon black surface and will be discussed now.

\section{Discussion}

We will first consider two models which were previously proposed in the literature and depicted in Fig. 6A and B.

The Donnet and Custodero model (Fig. 6A), based on STM observation, proposed a fish-like scale structure former by the graphitic domains, but gives no assumption about the structures existing at the edge of these "fish scales".

On the other hand, the Schuster et al. model (Fig. 6B), mainly from the distribution functions of the adsorption energies of ethene, suggested the existence of four types of adsorption sites bound to, (1) graphitic planes, (2) amorphous carbon, (3) crystallite edges and (4) slit shaped cavities.

The three first types of adsorption sites cannot be at the origin of any important exclusion size phenomena of the cyclooctane probe. Only the slit shaped sites could be at the origin of any size exclusion effect, but such default could not be observed by the STM.

Moreover, neither the Donnet and Custodero's nor the Schuster's model allows us to predict the correlation existing between the variation of both $\gamma_{s}^{d}$ and $I_{\mathrm{M}}$ parameters with the $\mathrm{PBu}$
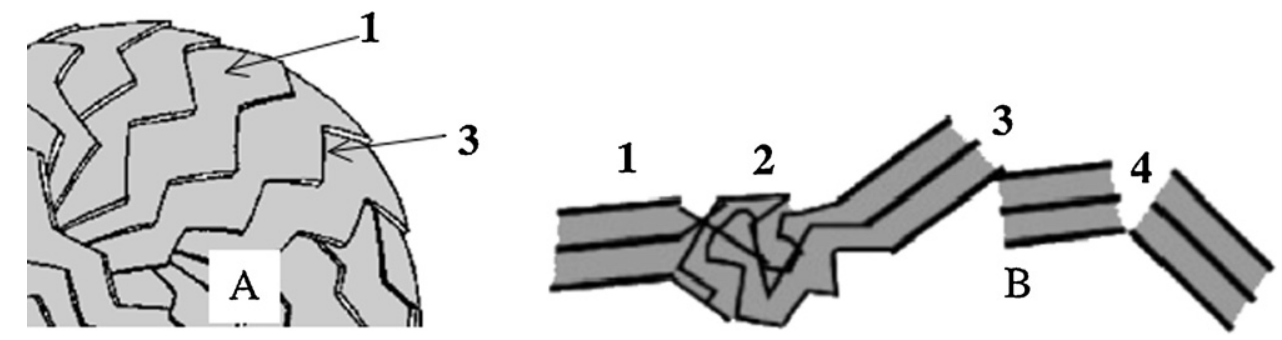

Fig. 6. Schematic representations of the carbon black surface topology according to Donnet and Custodero [29,30], on left, and Schuster and al. [15], on right. (1) Graphitic planes, (2) amorphous carbon, (3) crystallite edges and (4) slit shaped cavities. 


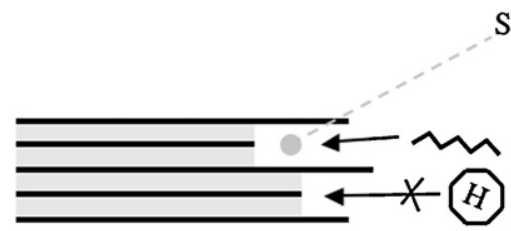

A

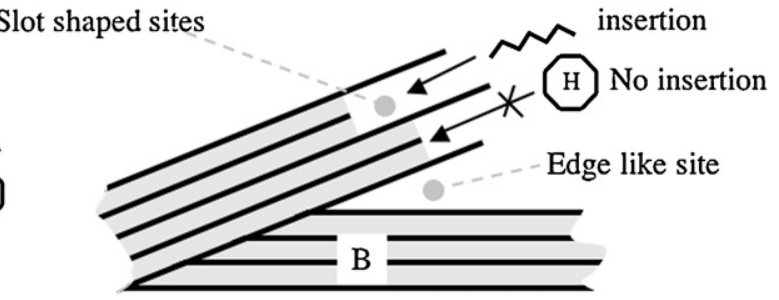

Fig. 8. Schematic representation of the insertion size of linear alkanes for layered solids (A) like talc or graphite and for a "fish scale" structure (B) present on the carbon black surface.

impregnation ratio as it is observed, for example, for example in the N115 sample, as shown in Fig. 7.

In particular, the previous models do not allow us to explain the fact that there is a decrease in the value of $\gamma_{s}^{d}$ whereas the $I_{\mathrm{M}}$ value remains weak and quite constant, increasing only slowly from 0.3 to 0.4 values.

We will come back to previous studies led on crystalline silicas [41], talcs [31,36,37] and graphites [42]. These solids exhibit high $\gamma_{s}^{d}$ and low $I_{\mathrm{M}}$ values. In order to explain such size exclusion effect of cyclic alkanes, it was suggested that the linear alkanes might enter in the slot shaped sites present on the crystalline lateral surfaces due to gaps left by missing crystal plane, as drawn in Fig. 8A, on the left.

Depositing PEG on the talc surface, Comard and al. [31,37] had observed a very similar variation of both $\gamma_{s}^{d}$ and $I_{\mathrm{M}}$ parameters with the PEG impregnation ratio than that shown for the N115 sample for the PBU progressive impregnation.

Such variation could only be explained when one admits that the flexible and polar PEG chain will be absorbed at first on the lateral surfaces of the talc crystallite, shielding progressively the slot shaped site, hindering the insertion of linear alkane, inducing a rapid decrease of the $\gamma_{s}^{d}$ value, which starts immediately at the first stage of impregnation process. Correspondingly, as long as the slot shaped insertion sites remain accessible, the $I_{\mathrm{M}}$ parameter remains almost equal to the initial value measured on the unmodified talc. Once, these sites are completely hidden, the $I_{\mathrm{M}}$ parameter start to increase until the entire surface is covered by a continuous polymer layer.

The same process will allow us to explain the variation of the carbon black surface under the controlled PBu impregnation due to the progressive shielding of the slot like sites present on the lateral surfaces of the graphitic structures.

Now a question is raised, how to explain that the N115 sample behaves very differently from the N330 and N539. The answer could be found when considering the variations in the surface roughness assessed by comparing surface areas obtained with CTAB $\left(S_{\text {CTAB }}\right)$, nitrogen $\left(S_{\mathrm{N}_{2}}\right)$ or the iodide adsorption number $N_{\mathrm{I}_{2}}$. It has been observed that under a specific surface area [43], the $S_{\mathrm{CTAB}}$ and $N_{\mathrm{I}_{2}}$ are very close, but over this threshold $S_{\mathrm{CTAB}}$ becomes clearly lower than $N_{\mathrm{I}_{2}}$, indicating an increase of the surface roughness.

Moreover, when considering the variation in the $S_{\mathrm{CTAB}} / S_{\mathrm{N}_{2}}$ ratio, versus the mean diameter of the primary particle assessed by TEM, one can see this ratio increases quickly for carbon blacks that have a particle diameter lower than $30 \mathrm{~nm}$. Over this critical value, it remains quite constant and overcomes slightly 1 as depicted in Fig. 9.

Hence, the differences in behaviour observed between the N115 $\mathrm{CB}$ and the other samples have to be attributed to their differences in surface roughness. This surface roughness originates from the temperature of the formation of the $\mathrm{CB}$. The $\mathrm{N} 115 \mathrm{CB}$ is formed at a higher temperature than the N330 and, of course the N539 [43,44]. At this temperature, the graphitic domains present on the surface would be more organised leading to an increase of the number of slot shaped sites on the edges of the graphitic scales and so, leading

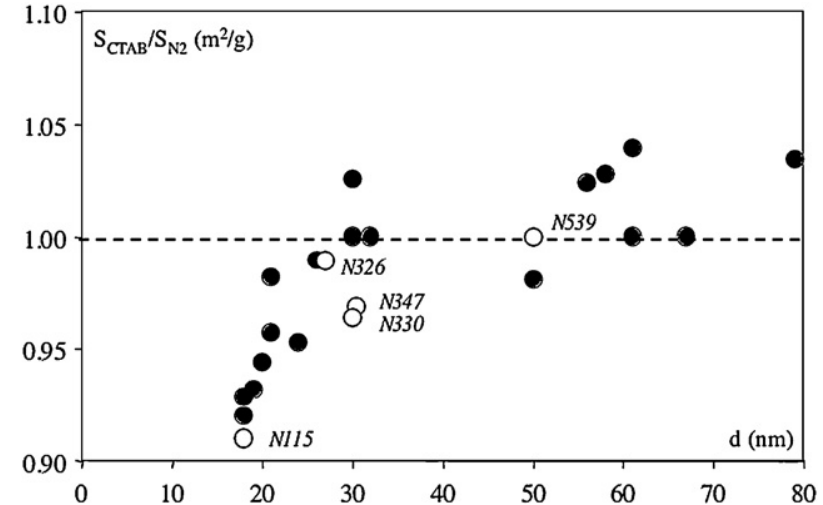

Fig. 9. Variation $C T A B /$ nitrogen specific surface areas ratio with the mean diameter (d) of the carbon blacks primary particles. Open circles correspond to our carbon blacks samples, closed circles are extracted from literature data [43].

to high energetic adsorption sites of the n-alkanes and correspondingly a more intensive exclusion size phenomenon of cyclooctane as depicted in Fig. 8B above. At a lower temperature of formation, the organisation degree of the graphitic crystallites becomes much lower, and both insertion and exclusion phenomena become less important.

This interpretation is also supported by the fact that the variations of the IGC-ID parameters depend on the nature of both the polymer and the solid. Influence of the nature of the adsorbed polymer was clearly demonstrated by Comard et al. [36] in the case of talc as adsorbant.

\section{Conclusion}

In conclusion, monitoring the variation of the dispersive component of the surface energy $\left(\gamma_{s}^{d}\right)$ and the index of nanomorphology $\left(I_{\mathrm{M}}\right)$, is an excellent method to follow the variations in the surface properties of $\mathrm{CB}$ impregnated with increasing ratios of $\mathrm{PBu}$.

It has been observed that there is a clear correlation between the decrease in the $\gamma_{s}^{d}$ and the increase in the $I_{\mathrm{M}}$.

This variation is due to the fact that the flexible, and not very polar, PBu chain will adsorb at first on the lateral surfaces of the graphitic domains present on the surface of the $C B$ according to the models proposed in the literature. The PBu macromolecules will then shield progressively the slot shaped site, hindering the insertion of linear alkane, resulting in a rapid decrease of the $\gamma_{s}^{d}$ value.

As long as the slot shaped insertion sites remain accessible, the $I_{\mathrm{M}}$ parameter remains quite equal to the initial value measured on the unmodified CB. Once these sites are completely covered, the $I_{M}$ parameter starts to increase to one until the entire surface is covered by a continuous polymer layer corresponding to the formation of a so called MU monolayer.

However, if the N539, the N326, the N330 and the N347 CB behave similarly, the variations of the surface properties of the 
N115 sample are different. The literature data suggests that the N115 presents a rougher surface having a higher graphitic character due to a higher temperature of synthesis than the other studied samples.

Hence, the coupling of the IGC-ID with the controlled modification by $\mathrm{PBu}$ impregnation permits us:

- To get information on the surface morphology of a CB and especially on its surface heterogeneity.

- To estimate quantitatively the number of sites having the highest interaction energy; sites that could not be quantified by either gas adsorption because surface roughness generates a negligible microporous volume, or by AFM that allows only to observe the sole structure of the graphitic domains.

- To highlight the specific interaction that the PBu exchanges with this type of site, which may be responsible of the reinforcing capacity of the CBs towards elastomers.

- To prove clearly the differences in surface properties between CBs of different grades.

\section{References}

[1] G. Kraus, Reinforcement of Elastomers by Carbon Black, Wiley Interscience, New York, 1965

[2] J.B. Donnet, R.C. Bansal, M.-J. Wang, Carbon Black Science and Technology Marcel Dekker Inc., New York, 1993.

[3] M. Gerspacher, C.P. O'Farrell, L. Nikiel, H.H. Yang, F. Le Méhauté, Rubber Chem Technol. 69 (1996) 786

[4] M. Klüppel, R.H. Schuster, G. Heinrich, Rubber Chem. Technol. 69 (1996) 786.

[5] M. Klüppel, Adv. Polym. Sci. 164 (2003) 1.

[6] M. Klüppel, J. Meier, M. Dämgen, Modeling of stress softening and filler induced hysteresis of elastomer materials, in: P.-E. Austrell, L. Kari (Eds.), Constitutive Models for Rubber IV, A.A. Balkema Publishers, Lisse, Abingdon, Exton, Tokyo, 2005.

[7] M. Klüppel, G. Heinrich, Kautsch. Gummi Kunstst. 58 (2005) 217.

[8] C. Lansinger, J.B. Donnet, Kautsch. Gummi Kunstst. 45 (1992) 459.

[9] M.-J. Wang, S. Wolff, Rubber Chem. Technol. 65 (1992) 715.

[10] E. Papirer, S. Li, H. Balard, J. Jagiello, Carbon 29 (1991) 1135

[11] E. Papirer, J.-B. Donnet, J. Heinkele, J. Chem. Phys. 68 (1971) 580.

[12] J.-B. Donnet, Carbon 32 (1994) 1305.
[13] H. Balard, E. Brendlé, E. Papirer, Determination of acid-base properties of solids surfaces using inverse gas chromatography: advantages and limitations, in: K. Mittal (Ed.), Acid-Base Interactions: Relevance to Adhesion Science and Technology, VSP, Utrecht (Nederlands), 2000, pp. 299-316.

[14] A. Lapra, E. Custodero, N. Simon, Kautsch. Gummi Kunstst. 57 (2004) 52.

[15] A. Schröder, M. Klüppel, R.H. Schuster, Macromol. Mater. Eng. 292 (2007) 885.

[16] H. Balard, E. Papirer, Polym. Mater. Sci. Eng. 70 (1994) 456.

17] E. Papirer, E. Brendlé, H. Balard, F. Ozil, Carbon 37 (1999) 1265

[18] T.A. Vilgis, G. Heinrich, Macromolecules 27 (1994) 7896.

[19] T.W. Zerda, H. Yang, M. Gerspacher, Rubber Chem. Technol. 65 (1992) 130.

[20] I.M.K. Ismail, P. Pfeifer, Langmuir 10 (1994) 1532.

[21] W. Xu, T.W. Zerda, H. Yang, M. Gerspacher, Carbon 34 (1996) 165

[22] F. Ehrburger-Dolle, M. Holz, J. Lahaye, Pure Appl. Chem. 65 (1993) 2223.

[23] B. Sahouli, S. Blacher, F. Brouers, Langmuir 12 (1996) 2872

[24] H. Darmstadt, C. Roy, S. Kallaguine, B. Sahouli, S. Blacher, R. Pirard, F. Brouers, Rubber Chem. Technol. 68 (1995) 32.

[25] W. Niedermeier, H. Raab, J. Stiersdorfer, S. Kreitmeier, D. Göritz, Kautsch. Gummi Kunstst. 47 (1994) 799.

[26] H. Raab, J. Fröhlich, D. Göritz, Kautsch. Gummi Kunstst. 3 (2000) 137

[27] M.H. Reich, S.P. Russo, J.K. Snook, H.K. Wagenfold, J. Colloid Interface Sci. 135 (1990) 353.

[28] J. Fröhlich, S. Kreitmeier, D. Göritz, Kautsch. Gummi Kunstst. 51 (1998) 370.

[29] E. Custodéro, PhD Thesis, University of Haute Alsace, Mulhouse, France, 1992.

[30] J.B. Donnet, E. Custodéro, Carbon 30 (1992) 813

[31] M.P. Comard, R. Calvet, J.A. Dodds, H. Balard, Powder Technol. 128 (2002) 262

[32] ASTM D 3037, Annual Book of ASTM Standards, 9.01, 1990, p. 465.

33] ASTM D 3765, Annual Book of ASTM Standards, 9.01, 1990, p. 614

[34] ASTM D 1510, Annual Book of ASTM Standards, 9.01, 1990, p. 269.

[35] S. Hamdi, B. Hamdi, Z. Kessaissia, H. Bathel, H. Balard, J.B. Donnet, J. Chromatogr A 969 (2002) 143

[36] M.P. Comard, R. Calvet, H. Balard, J.A. Dodds, Colloids Surf. A 232 (2004) 269.

37] M.P. Comard, R. Calvet, H. Balard, J.A. Dodds, Colloids Surf. A 238 (2004) 37.

[38] J.R. Conder, C.L. Young, Physicochemical Measurements by Chromatography, John S. Wiley \& Sons, New York, 1979.

[39] E. Brendlé, E. Papirer, J. Colloid Interface Sci. 194 (1997) 207.

40] G.M. Dorris, D.G. Gray, J. Colloid Interface Sci. 77 (1980) 353.

[41] E. Papirer, H. Balard, Surface energy of silicas, in: A.P. Legrand (Ed.), The Surface Properties of Silicas, J. Wiley \& Sons, NY, 1998, pp. 315-364 (Chapter 3).

[42] H. Balard, D. Maafa, A. Santini, J.B. Donnet, J. Chromatogr. A 1198 (2008) 173.

[43] G. Kühner, M. Voll, Manufacture, in: J.B. Donnet, R.C. Bansal, M.-J. Wang (Eds.), Carbon Black Science and Technology, Marcel Dekker Inc., New York, 1993, p. 32.

[44] W.H. Hess, C.R. Herd, Physical properties, in: B. Donnet, R.C. Bansal, M.-J. Wang (Eds.), Carbon Black Science and Technology, Marcel Dekker Inc., New York, 1993, p. 113 